\title{
Senegal: The impact of a study on misoprostol use and knowledge among pharmacists
}

\author{
Eva Burke \\ E. Robinson \\ Nafissatou Diop \\ Population Council \\ Kate Reiss \\ Katharine Footman
}

See next page for additional authors

Follow this and additional works at: https://knowledgecommons.popcouncil.org/departments_sbsr-rh

Part of the Demography, Population, and Ecology Commons, Family, Life Course, and Society Commons, Gender and Sexuality Commons, International Public Health Commons, Maternal and Child Health Commons, Pharmacy and Pharmaceutical Sciences Commons, Public Health Education and Promotion Commons, and the Women's Health Commons How does access to this work benefit you? Let us know!

\section{Recommended Citation}

Burke, Eva, E. Robinson, Nafissatou Diop, Kate Reiss, Katharine Footman, Maaike Van Min, Barbara Reichwein, and lan Askew. 2016. "Senegal: The impact of a study on misoprostol use and knowledge among pharmacists." London: Marie Stopes International. 


\section{Authors}

Eva Burke, E. Robinson, Nafissatou Diop, Kate Reiss, Katharine Footman, Maaike Van Min, Barbara Reichwein, and Ian Askew

This case study is available at Knowledge Commons: https://knowledgecommons.popcouncil.org/departments_sbsr- 


\section{SENEGAL: the impact of a study on misoprostol knowledge and use amongst pharmacists}

STEP UP generates policy-relevant research to promote an evidencebased approach for improving access to family planning and safe abortion.

We work in Bangladesh, northern India, Ghana, Kenya, and Senegal.

Population Council Coordinating Partner

African Population and Health Research Center icddr.b

London School of Hygiene and Tropical Medicine

Marie Stopes International

Partners in Population and Development

Funded by

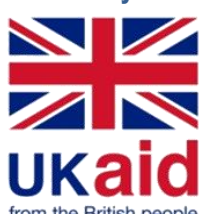

\section{FROM EVIDENCE TO IMPACT: A look at how STEP UP research was used to impact policies and programmes}

The goal of family planning and reproductive health operations research is to generate evidence that helps policies and programmes maximize access to and quality of services for women and their families. Yet the crucial step of ensuring the utilization of that evidence often receives inconsistent or inadequate attention. There is relatively little monitoring and reporting on whether and to what effect project results are utilized, or on the nature, process, and efficacy of the strategies employed to achieve this.

The goal of this case study is to document an activity of the STEP UP research programme consortium which resulted in successful evidence utilization. This is to both demonstrate the positive impact STEP UP is having on family planning and reproductive health policies, as well as to document the process by which this was achieved so as to inform future research of successful strategies and lessons learned.

\section{SUMMARY}

The availability of misoprostol is a key part of improving maternal health in low- and middleincome countries. In Senegal, where the drug is not widely available, pharmacies are one of the few places women can access it.

STEP UP conducted a study to understand misoprostol knowledge and provision in these pharmacies. Stakeholder uptake of the results brought about several important achievements:

- Expansion of MSI's regional programme strategy to include training of both pharmacists and health care providers;

- Provision of information on the legal status and correct regimen of Misoclear during pharmaceutical detailer visits, to improve pharmacists' knowledge of and confidence to purchase and sell misoprostol.

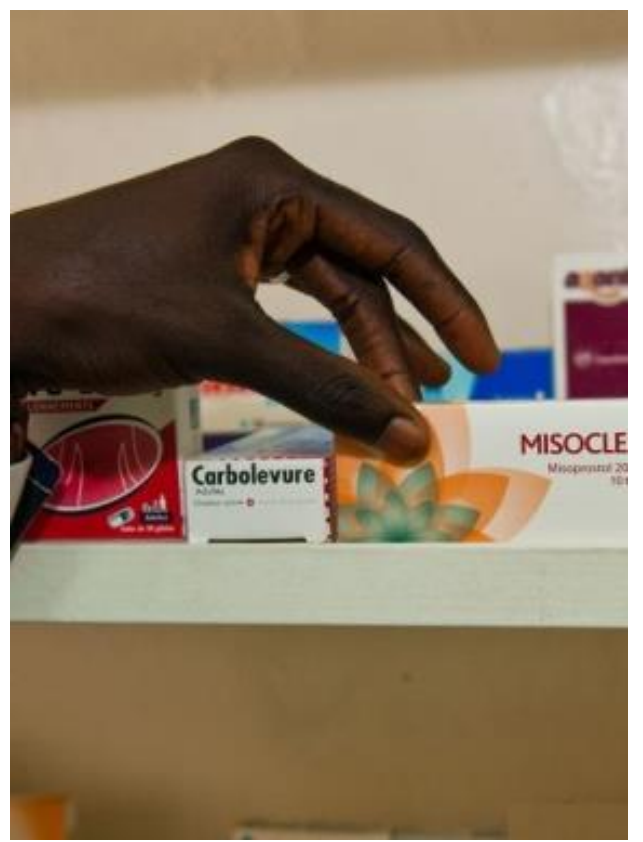

- A commitment from the Ministry of Health to train pharmacists on misoprostol was secured. 


\section{INTRODUCTION}

Misoprostol is scarcely available in Senegal, despite being essential for the management of postpartum hemorrhage (PPH) and post-abortion care (PAC) and included on the List of Essential Medicines (EML) of both the World Health Organization (WHO) and the Senegalese Ministry of Health (MoH).

Misoprostol in Senegal can only be obtained via prescription, and is supplied almost exclusively by private sector facilities. It is not procured by the $\mathrm{MoH}$ for the public sector, with only $1 \%$ of public sector health providers reporting its use in 2013.

\section{THE PROJECT}

In 2013, Marie Stopes International (MSI) and the Population Council conducted a study on misoprostol knowledge and distribution practices amongst private pharmacies in Dakar. The study is part of the work undertaken by the "Strengthening Evidence for Programming on Unintended Pregnancy (STEP UP)" research consortium, with funding from DFID.

The aim of the study was to inform strategies to improve misoprostol provision in an effort to reduce maternal mortality, by gaining an understanding of the knowledge, attitudes and practices (KAP) of misoprostol provision amongst 110 private sector pharmacists in Dakar. The study took place in the context of governmental targets to reduce maternal mortality from 392 in 2010/11 to 127 deaths per 100,000 live births by the end of 2015 .

\section{KEY STUDY RESULTS}

- Only $35 \%$ of pharmacists sold misoprostol, of which the majority $(70 \%)$ reported selling it only for duodenal or gastric ulcers, rather than for gynaecological conditions such as postpartum haemorrhage (PPH) and post abortion care (PAC).

- Less than $5 \%$ of pharmacists knew misoprostol could be used for the management of PPH, none reported selling it for this purpose, and none knew the correct dosage.

- Only $13 \%$ of pharmacists knew misoprostol was registered for PAC; $3.7 \%$ reported selling it for this indication, but only $0.5 \%$ of all pharmacists knew the correct dosage.

- $51 \%$ of pharmacists reported not being confident providing misoprostol to clients.
- $38 \%$ of pharmacists knew that misoprostol can be used to induce abortion.

- Only one respondent reported having sold misoprostol to a client without a prescription;

- $48 \%$ of those not selling misoprostol expressed a desire to do so.

- $42 \%$ of those not stocking misoprostol stated that the reason was that they did not want to sell abortifacient products.

Fig. 1: Pharmacist reasons for not selling Misoprostol

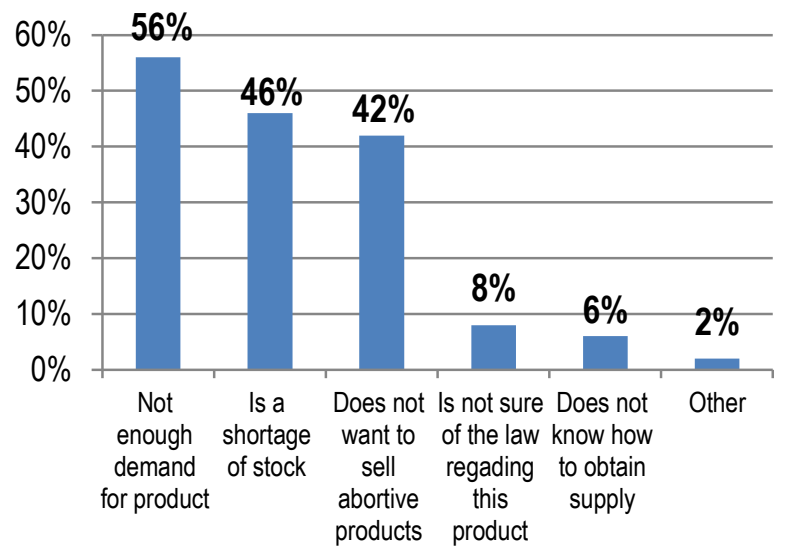

\section{MAKING AN IMPACT}

\section{Influencing policies and programming improvements}

This section presents how the evidence from the study was used, and what impact it had on access to misoprostol in Senegal.

\section{Expansion of MSl's programme strategy to include training of health care providers}

The low sales of misoprostol for gynecological indications reported by pharmacists were in part due to a lack of prescriptions issued by health care providers, such as doctors, nurse and midwives. As a result of the study, MSI broadened its strategy to include training of public providers, having previously focused on capacity building amongst pharmacists alone to increase access to misoprostol.

MSI Senegal collaborated with the Ministry of Health and Gynuity Health Projects to train 1020 public sector service providers in 35 districts on the uses of misoprostol by January 2015 , with plans to train another 1200 by late 2015. This strategy of training health care providers later became part of MSl's regional approach to scaling up access to misoprostol in West Africa. 


\section{Improving communication with pharmacists to build confidence to sell misoprostol}

Low knowledge of misoprostol registration status and regimen for gynaecological indications limited pharmacists' confidence in procuring and selling the product. In response, the pharmaceutical detailers responsible for marketing Misoclear (MSl's branded product) to pharmacists were re-trained on its use and their remit expanded, enabling them to share information on the legal status and correct provision of Misoclear. These topics are now covered during detailing visits with the aim of imparting knowledge and improving confidence to purchase and sell misoprostol.

The impact of this strategy is evidenced by the increase in the number of pharmacists who stock Misoclear from 253 in December 2014 to 415 pharmacists in June 2015. ${ }^{1}$

\section{Commitment by the Ministry of Health to train pharmacists on misoprostol}

Two dissemination events were held, co-hosted with the Directorate of Reproductive Health and Child Survival (DSRSE). These events provided opportunities for MSI Senegal and the Population Council to highlight the importance of misoprostol and its contribution to reducing maternal mortality in Senegal to stakeholders and the media. At the second dissemination event, the $\mathrm{MoH}$ committed to training pharmacists on all essential medicines, including misoprostol. The events were a result of the strong relationship between the study team and the DSRSE.

\section{Who will benefit?}

Through these improvements in service access, quality, and political and programmatic support, there is the potential that benefits will be seen at a number of levels:

- Individuals: Fewer women may suffer or die of treatable maternal health conditions like PPH and PAC by using misoprostol. Not only will they be able to obtain this lifesaving drug from more locations, but the improved skills of public sector providers and pharmacists may result in better quality services.

- Communities: Women play central roles in family and community life. By improving access to misoprostol, preventable deaths and diseases may be avoided, helping to keep communities stable and healthy.

- National goals: Senegal's goal of reducing maternal mortality from 392 in 2010/11 to 127 deaths per 100,000 live births by the end of 2015 is made more attainable by this progress towards making misoprostol more available to women who need it.

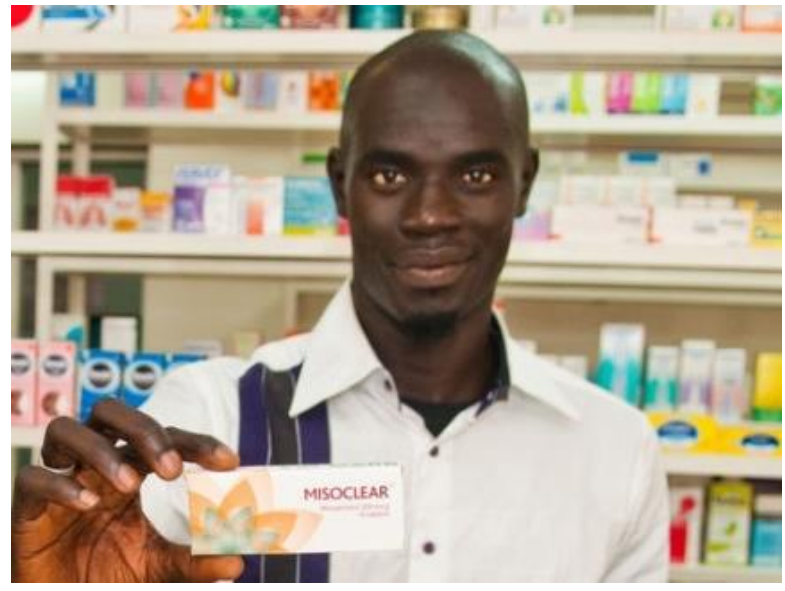

HOW WAS IMPACT ACHIEVED? SOME KEY LESSONS LEARNED

\section{Strong relationships with policymakers}

The two dissemination events that contributed to the Ministry of Health's commitment to train pharmacists on misoprostol were the result of the strong relationship between the study team and the DSRSE. Not only did the events enable widespread dissemination of information on misoprostol's role in reducing maternal mortality, but they were also cohosted with the DSRSE; this helped to promote the Ministry's ownership of the study's recommendations. The director of the DSRSE is also a supporter of improving women's access to evidence-based family planning and reproductive health services, and his commitment enabled further support and utilization of the study's findings.

\section{Support of the Order of Pharmacists}

The involvement of the Order of Pharmacists from project inception was essential for building ties with the pharmacists involved in the study. The Order provided the list of pharmacies in Dakar, and prior to data collection they sent informational letters to the pharmacies to introduce them to the project. This enabled early links with pharmacists, and may have bolstered their engagement with the research team as well as their receptiveness to the more accurate information shared by the re-trained pharmaceutical detailers who market and explain the legal status and uses of Misoclear. 


\section{CONCLUSION}

By evidencing barriers to misoprostol access and provision, this study raised awareness for a little understood public health issue that continues to contribute to maternal mortality in Senegal.

The MoH's commitment to training public providers and pharmacists on all products on the essential medicines list is a promising step towards bettering the health of women in Senegal. At the time of writing, the pharmacy training had not yet been brought to fruition.

Further research is needed to investigate the knowledge, attitudes and practices of service providers responsible for prescribing misoprostol, as well as the impact that training such providers will have on use of the product.

MSI Senegal continues to work to build the capacity of healthcare providers in the public sector, while both MSI Senegal and the Population Council remain committed to supporting the $\mathrm{MoH}$ to reduce levels of maternal mortality from PPH and PAC.

\section{By evidencing barriers to misoprostol access and provision, this study raised awareness for a little-understood public health issue that continues to contribute to maternal mortality in Senegal.}

Suggested citation:

Burke, E., Robinson, E., Diop, N., Reiss, K., Footman, K., Reichwein, B, van Min, M., Askew, I. 2016.

"Senegal: the impact of a study on misoprostol knowledge and use amongst pharmacists," STEP UP Case Study, 2016. London: Marie Stopes International.

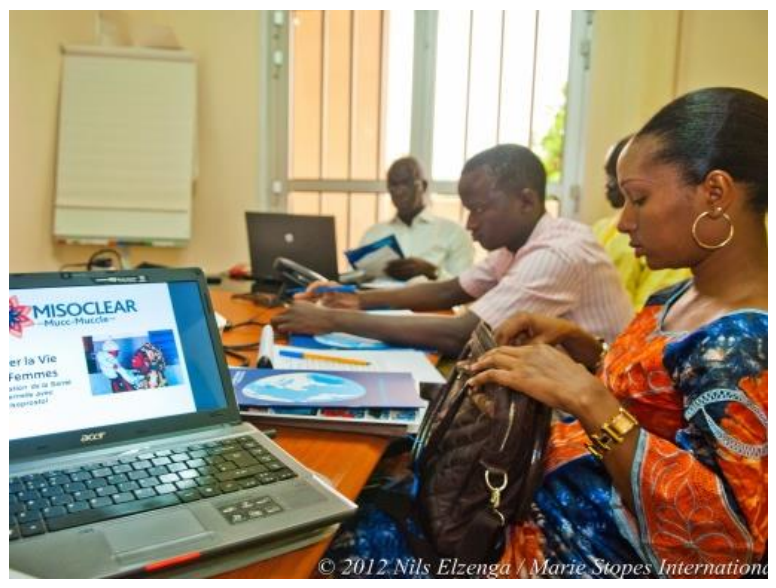

\section{REFERENCES AND SUGGESTED READINGS}

1. Agence Nationale de la Statistique et de la Démographie (ANSD) [Sénégal] et ICF International. 2012. Enquête Continue sur la Prestation des Services de Soins de Santé, (ECPSS) du Sénégal 2012-2013. Calverton, Maryland, USA : ANSD et ICF International. P, 36

2. Gaye A., Diop A., Shochet T., Winikoff B., 2013, Decentralizing post-abortion care: misoprostol for incomplete abortion in Senegal, BMC Pregnancy and Childbirth 2012, 12:127

3. Childfund, Gynuity, 2014, Étude de deux stratégies pour la prévention des hémorragies du post-partum au niveau communautaire : misoprostol et ocytocine en Uniject, Dissémination National, Janvier 2014

4. Childfund, Gynuity, 2013, Étude de deux stratégies pour la prévention des hémorragies du post-partum au niveau communautaire : misoprostol et ocytocine en Uniject, Dissémination National, Janvier 2014

5. Ndao, R., Mane, B., Burke, E., Diop, N., Reiss, K., van Min, M., 2014, "Knowledge and provision practices of misoprostol among pharmacies in Senegal. STEP UP Research Report," Dakar, Marie Stopes International \& Population Council

6. Ortiz C., Sylla A., Diadhou M., Dieng T., Mall I., Sloan N. December 2010. Preventing Postpartum Hemorrhage at the Community Level in Senegal with Misoprostol. Bethesda, MD: Health Systems 20/20 project, Abt Associates Inc. 